\title{
Does wearing double surgical masks during the COVID-19 pandemic reduce maternal oxygen saturation in term pregnant women?: A prospective study
}

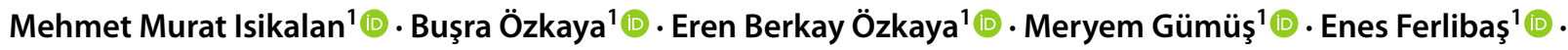 \\ Ali Acar ${ }^{1}(1)$
}

Received: 5 February 2021 / Accepted: 12 June 2021 / Published online: 18 June 2021

(c) The Author(s), under exclusive licence to Springer-Verlag GmbH Germany, part of Springer Nature 2021

\begin{abstract}
Purpose This study aimed to compare the effects of using single and double surgical masks (SM) on maternal oxygen saturation in pregnant women.

Methods In this prospective study, single or double SM were worn by term pregnant women who applied for routine controls. The vital signs of the participants such as oxygen saturation, pulse, respiratory rate, fever, systolic and diastolic blood pressure were measured at admission and 30 min later.

Results There were 223 participants in the single SM group and 231 participants in the double SM group. Thirty minutes after putting on the mask, there was no significant difference in the proportion of patients whose oxygen saturation fell below 95 (3.6 vs 5.6\%, $p=0.301$ ). No significant difference was observed between the admission and 30 min oxygen saturation levels of the pregnant women in the single SM group. However, maternal oxygen saturation after 30 min of the pregnant women in the double SM group was significantly lower $(97.4 \pm 1.1$ vs $96.6 \pm 1.3, p<0.001)$. No significant changes were observed in the vital signs of either groups.

Conclusion When using double SM, oxygen saturation is significantly reduced compared to pre-mask values. Nevertheless, it seems difficult to say that these decreases have clinical significance.
\end{abstract}

Keywords COVID-19 $\cdot$ Double mask $\cdot$ Oxygen saturation $\cdot$ Surgical mask $\cdot$ Term-pregnancy

\section{Introduction}

Mehmet Murat Isikalan

muratisikalan@gmail.com

Buşra Özkaya

drbusracubuk@gmail.com

Eren Berkay Özkaya

erenberkay92@hotmail.com

Meryem Gümüş

meryemgumusm@gmail.com

Enes Ferlibaş

dr_eferlibas@hotmail.com

Ali Acar

draliacar42@yahoo.com

1 Department of Gynecology \& Obstetrics, Meram Faculty of Medicine, Necmettin Erbakan University, Konya, Turkey
At the end of 2019, a novel coronavirus (SARS-CoV-2) was identified as a pneumonia agent and it spread all over the world in a short time. All countries are struggling with the Coronavirus 2019 (COVID-19) infection, which has been declared a pandemic by the world health organization [1]. COVID-19 infection is thought to be transmitted by small droplets that are dispersed through speech, breathing, coughing or sneezing [2]. Therefore, restrictions in social relationships, avoiding traveling and staying at home were suggested to the public to reduce human-to-human transmission [3].

Face masks are the critical components of personal protective equipment, especially for healthcare workers dealing with infectious diseases $[4,5]$. The use of masks during the Covid-19 pandemic has been proven to be protective against the virus. After the pandemic declaration, many organizations, including the World Health Organization, recommended that everyone use masks in public places to limit 
the spread of Sars-Cov-2 [6, 7]. In many countries, wearing a mask has been made compulsory and it is prohibited to enter health institutions without a mask.

The severity of COVID-19 infection in pregnant and nonpregnant women is similar, but pregnant women are exposed to the same risk distribution at younger ages [8]. In some studies, it was determined that pregnant women need more intensive care and mechanical ventilation [9]. It has also been suggested that COVID-19 infection may cause preterm birth and fetal growth restriction in pregnant women [10].

It is common for pregnant women to wear double surgical masks (SM) in public places (hence in health institutions) because they feel more secure and believe that protection is increased. Studies on the use of masks in pregnant women are extremely limited. To the best of our knowledge, there is no study conducted on the effect of wearing double SM on maternal oxygen saturation in pregnant women. The aim of this study was to investigate the effects of using single vs double SM on maternal oxygen saturation and other vital signs in pregnant women.

\section{Material and methods}

This study was designed as a prospective longitudinal study and approved by the University Ethics Committee (approval number: 2020/2858). The study was conducted according to the Helsinki declaration and the informed consent of all participants was obtained.

The $\mathrm{G} *$ Power 3.1 statistical analysis program (Dusseldorf, Germany) was used to calculate the power of the study. The $\alpha$ error probability, effect size and power of the study were determined as $0.05,0.20$ and 0.90 , respectively. Accordingly, the required sample size for each group was 216.

The study was conducted between October 23, 2020 and January 26, 2021. Healthy singleton pregnant women over 37 weeks who applied to a university hospital obstetrics outpatient clinic for normal obstetric examination were included in the study. Women with an active upper respiratory infection, fever, morbid obesity, multiple pregnancies, smoking, chronic lung disease, obstetric emergencies, unwillingness to participate in the study, and those whose initial oxygen saturation was below 95 percent were excluded from the study.

After a routine prenatal visit, patients who agreed to participate in the study were randomized. The height and weight of all participants were measured. Demographic and obstetric histories were recorded. The gestational age was calculated according to the last menstrual period and confirmed by an early period ultrasound in the first trimester. If there is a difference of more than a week, the early period ultrasound was taken as basis. After letting the participants rest for $10 \mathrm{~min}$, their temperature, pulse, oxygen saturation and blood pressure were measured in a sitting position. Oxygen saturation was measured from the index finger with the same model finger type pulse oximetry devices (Berry®, China). Fever was measured from the frontal region with an infrared fever thermometer (Braun ${ }^{\circledR}$, Germany). Single or double SM were given for them to put on after the researchers gave instructions for using the product. All participants wore the same brand of SMs that comply with ISO standards (B-good $®$, Honnes, Turkey).

While wearing the masks (single or double), the participants performed a non-stress test (NST) in the left lateral position. The oxygen saturation, fever, maternal heart rate and blood pressure of the participants were measured in the sitting position $30 \mathrm{~min}$ after putting on the mask. Participants were asked about their tolerance of the mask at this stage. They were asked to give a score of $1-10$. The study continued until a sufficient sample size was reached in both groups (single and double masks).

\section{Statistical analysis}

All the data collected were analyzed using the Statistical Package for the Social Sciences, version 23, SPSS Inc., Chicago, IL (SPSS). Descriptive characteristics were calculated for the relevant variables. The normal distributions of the data were evaluated with the Kolmogorov-Smirnov test and histograms. Continuous and categorical variables were given as median $(25,75 \%$ interquartile range $)$, mean \pm standard deviation or number (\%). The independent samples $T$ test, the paired samples $T$ test, the Chi-squared test and logistic regression analyses were used.

\section{Results}

A total of 454 eligible pregnant women participated in the study. There were 223 patients in the single SM group and 231 patients in the double SM group. The mean age of the pregnant women participating in the study was $28.3 \pm 5.7$. The gestational age of the pregnant women at the time of admission was $37.9 \pm 0.9$ weeks. There was no significant difference in age, body mass index (BMI), parity, gravidity, gestational age in the groups at admission. In addition, there was no significant difference between the baseline values of fever, maternal heart rate, respiratory rate and blood pressure of the two groups (Table 1).

In the single SM group, no significant difference was observed between the oxygen saturations measured at the time of admission and 30 min later. In the double SM group, the maternal oxygen saturations after 30 min were significantly lower than pre-mask levels $(97.4 \pm 1.1$ vs $96.6 \pm 1.3$, $p<0.01$ ) (Fig. 1). Nonetheless, there was no significant 
Table 1 Comparison of demographic characteristics and vital signs at admission

\begin{tabular}{llll}
\hline & $\begin{array}{l}\text { Single surgical mask } \\
\text { group }(n=223)\end{array}$ & $\begin{array}{l}\text { Double surgical } \\
\text { mask group }(n=231)\end{array}$ & $P$ value \\
\hline Age $($ years) & $28.7 \pm 5.7$ & $27.9 \pm 5.7$ & $0.141^{\mathrm{a}}$ \\
BMI $\left(\mathrm{kg} / \mathrm{m}^{2}\right)$ & $30.2 \pm 5.4$ & $29.8 \pm 4.6$ & $0.409^{\mathrm{a}}$ \\
Gestational age at admission (week) & $38.0 \pm 0.9$ & $37.9 \pm 1.0$ & $0.611^{\mathrm{a}}$ \\
Parity & $1(0,2)$ & $1(0,2)$ & $0.053^{\mathrm{b}}$ \\
Gravidity & $3(2,4)$ & $2(2,4)$ & $0.359^{\mathrm{b}}$ \\
Tolarence score for mask & $7.0 \pm 1.4$ & $6.4 \pm 1.8$ & $<\mathbf{0 . 0 0 1}^{\mathrm{a}}$ \\
Vital signs & & & \\
Oxygen saturation at admission & $97.3 \pm 1.0$ & $97.4 \pm 1.1$ & $0.238^{\mathrm{a}}$ \\
Oxygen saturation below 95 after 30 min & $8(3.6)$ & $13(5.6)$ & $0.301^{\mathrm{c}}$ \\
Fever at admission (centigrade) & $36.4 \pm 0.3$ & $36.4 \pm 0.3$ & $0.921^{\mathrm{a}}$ \\
Maternal heart rate at admission (beats $/ \mathrm{min})$ & $96.4 \pm 15.9$ & $94.4 \pm 12.9$ & $0.156^{\mathrm{a}}$ \\
Respiratory rate at admission (per min) & $19.3 \pm 1.5$ & $19.1 \pm 1.4$ & $0.085^{\mathrm{a}}$ \\
Systolic blood pressure at admission $(\mathrm{mmHg})$ & $110.3 \pm 10.0$ & $109.1 \pm 8.2$ & $0.172^{\mathrm{a}}$ \\
Diastolic blood pressure at admission $(\mathrm{mmHg})$ & $70.6 \pm 8.3$ & $70.1 \pm 8.5$ & $0.484^{\mathrm{a}}$ \\
\hline
\end{tabular}

$B M I$ body mass index

${ }^{\mathrm{a}}$ Data are presented as mean \pm standard deviation; ${ }^{\mathrm{b}}$ Median $\left(25 \%, 75 \%\right.$ interquartile range); ${ }^{\mathrm{c}} n(\%)$

$P$ values were obtained by the independent ${ }^{\mathrm{a}} T$ test; ${ }^{\mathrm{b}}$ the Mann Whitney $U$ test or the ${ }^{\mathrm{c}} \mathrm{Chi}$-Square Test

Significant $p$ values are shown in bold font

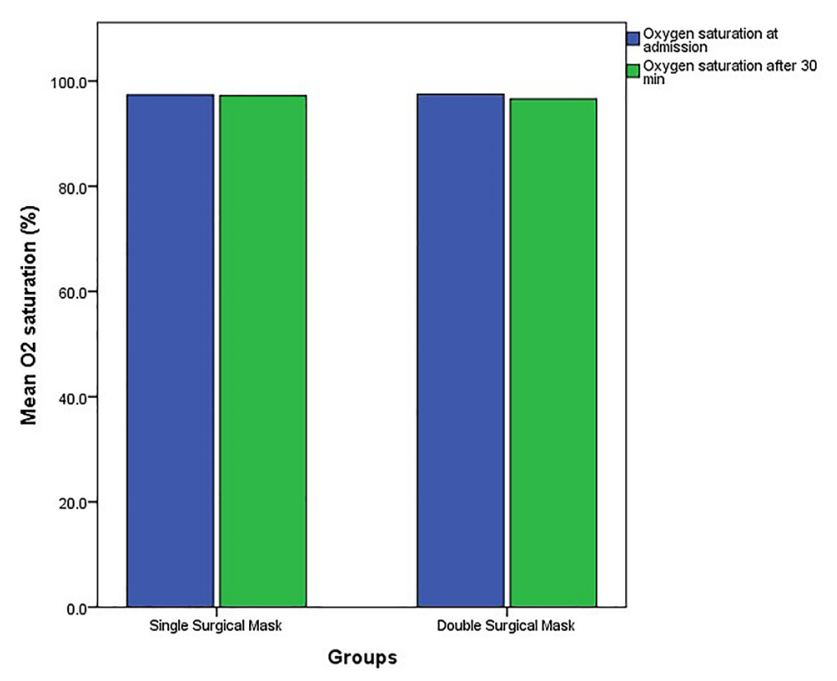

Fig. 1 Maternal oxygen saturation of pregnant women at admission and $30 \mathrm{~min}$ after putting on the masks

difference in the number of pregnant women whose oxygen saturation below 95 after $30 \min (3.6$ vs $5.6 \%, p=0.301$ ). There were no pregnant women in either group whose oxygen saturation $<92$ after wearing a mask (or masks).

Tolerance of the mask was significantly lower in the double SM group $(7.0 \pm 1.4$ vs $6.4 \pm 1.8, p<0.001)$.

No significant change was observed in the heart rate, systolic blood pressure, diastolic blood pressure, respiratory rate or fever values of the pregnant women in either group (Table 2).
There was no significant difference between the gestational age at delivery, route of delivery, newborn weights or 5th minute APGAR scores of the two groups (Table 3). When adjusted according to age and initial oxygen saturation, there was no increase in the probability of oxygen saturation decreasing below $95 \%$ after the use of double SMs (adjusted OR 1.82, 95\% confidence interval 0.65-3.94, $p=0.305$ ) (Table 4).

\section{Discussion}

In this study, the short-term effects of the use of single and double SM on maternal oxygen saturation and other vital signs in term pregnant women were investigated. It was observed that maternal oxygen saturation did not change in pregnant women wearing a single SM, but it decreased significantly in pregnant women wearing double SMs compared to pre-mask values. It was observed that the use of double SMs did not significantly change other vital signs such as pulse, systolic and diastolic blood pressures, respiratory rate and fever.

Physiological changes such as elevation of the diaphragm, decrease in functional residual capacity, increased ventilation and respiratory drive occur during pregnancy. Therefore, pregnant women have higher PO2 and lower PCO2 levels compared to non-pregnant women and have a compensated respiratory alkalosis. Mucosal edema and obstruction reach the highest level in the upper respiratory tract in the period close to term in pregnant women. Accordingly, 
Table 2 Vital signs of pregnant women at admission and 30 min after putting on the masks

\begin{tabular}{|c|c|c|c|c|c|c|}
\hline & \multicolumn{3}{|c|}{ Single surgical mask group } & \multicolumn{3}{|c|}{ Double surgical mask group } \\
\hline & At admission & After $30 \mathrm{~min}$ & $P$ value & At admission & After $30 \mathrm{~min}$ & $P$ value \\
\hline Oxygen saturation (\%) & $97.3 \pm 1.0$ & $97.2 \pm 1.2$ & 0.052 & $97.4 \pm 1.1$ & $96.6 \pm 1.3$ & $<0.001$ \\
\hline Maternal heart rate (beats/min) & $95.4 \pm 14.0$ & $94.3 \pm 13.8$ & 0.156 & $94 \pm 13$ & $94 \pm 14$ & 0.351 \\
\hline Systolic blood pressure $(\mathrm{mm} / \mathrm{Hg})$ & $100.7 \pm 10.4$ & $110.3 \pm 10.0$ & 0.520 & $110.3 \pm 8.7$ & $109.2 \pm 8.2$ & 0.061 \\
\hline Diastolic blood pressure $(\mathrm{mmHg})$ & $70.7 \pm 8.3$ & $70.0 \pm 7.9$ & 0.244 & $70.1 \pm 8.6$ & $69.5 \pm 9.1$ & 0.391 \\
\hline Respiratory rate (per min) & $19.3 \pm 1.5$ & $19.2 \pm 1.7$ & 0.286 & $19.1 \pm 1.4$ & $19.0 \pm 1.4$ & 0.340 \\
\hline Fever (centigrade) & $36.4 \pm 0.3$ & $36.4 \pm 0.2$ & 0.247 & $36.4 \pm 0.3$ & $36.4 \pm 0.2$ & 0.663 \\
\hline
\end{tabular}

NST non-stress test

Data are presented as mean \pm standard deviation

All $P$ values were obtained by the paired sample $T$ test

Significant $p$ values are written in bold font

Table 3 Comparison of obstetric and neonatal outcomes of the two groups

\begin{tabular}{clll}
\hline & $\begin{array}{l}\text { Single surgi- } \\
\text { cal mask group } \\
(n=223)\end{array}$ & $\begin{array}{l}\text { Double surgi- } \\
\text { cal mask group } \\
(n=231)\end{array}$ & $P$ value \\
\hline $\begin{array}{c}\text { Gestational age at } \\
\text { delivery (week) }\end{array}$ & $38.5 \pm 1.0$ & $38.5 \pm 1.0$ & $0.977^{\mathrm{a}}$ \\
$\begin{array}{c}\text { Route of delivery } \\
\text { Cesarean delivery }\end{array}$ & $151(76.3)$ & $188(83.9)$ & $0.051^{\mathrm{b}}$ \\
$\begin{array}{c}\text { Vaginal delivery } \\
\text { Newborn weight } \\
(\mathrm{g})\end{array}$ & $37(23.7)$ & $36(16.1)$ & \\
$\begin{array}{c}\text { 5 min APGAR } \\
\text { score }\end{array}$ & $7(7-8)$ & $3199.3 \pm 531.9$ & $0.170^{\mathrm{a}}$ \\
\hline
\end{tabular}

${ }^{\mathrm{a}}$ Mean \pm standard deviation, independent $T$ test

${ }^{\mathrm{b}}$ Number (\%), the Chi-square test

${ }^{\mathrm{c}}$ Median (25\%, 75\% IQR), Mann-Whitney $U$ test

it would not be surprising that mask studies in the pregnant population are different from the non-pregnant population.

Person et al. and Chen et.al investigated the effects of 5-6 min of short walking on vital signs in non-pregnant individuals wearing masks. In these studies, no changes were found in parameters such as oxygen saturation, heart rate and blood pressure in individuals using both N95 and SMs $[11,12]$.

In a study by Roberge et al. conducted on a total of 22 pregnant women in the second and third trimesters, it was stated that the use of N95 masks did not reduce oxygen saturation even during physical activity [13]. In that study, the number of participants was limited and the pregnant women were at different gestational weeks. Considering that the physiological changes occurring in the respiratory system during pregnancy vary according to gestational weeks, it can be thought that such studies will yield different results in different weeks of gestation. In contrast, the present study consists only of term pregnant women.

Tong et al. investigated the effects of long-term use of N95 masks on healthy pregnant women at 27-32 weeks of gestation [14]. In this study, a $23 \%$ reduction in maternal tidal volume occurred in pregnant women using N95 masks, but no change was found in maternal oxygen saturation and maternal and fetal heart rates. In a study conducted by Toprak et al. During the COVID-19 pandemic period, it was observed that the use of N95 or SMs in term pregnant women significantly decreased maternal oxygen saturation [15]. It was determined that this decrease was more pronounced with the N95 mask. In the aforementioned study, no analysis was made regarding whether the decreases in maternal oxygen saturation were below the clinically significant level of 95 percent. In the present study, it was observed that the use of a single SM did not show a significant decrease in maternal oxygen saturation in term pregnant women. However, it was observed that the use of double SMs resulted in a decrease in maternal oxygen saturation. No significant difference was found in the number of pregnant women whose maternal oxygen levels were below 95 percent. Pregnant women use surgical masks more often. One of the reasons is that respiratuar masks are more expensive. Pregnant women who cannot reach the FFP2 and FFP3
Table 4 Odds ratios in double surgical mask group compared to single surgical mask group

\begin{tabular}{lll}
\hline & Crude OR (95\% CI) & Adjusted OR (95\% CI) \\
\hline Oxygen saturation after 30 $\min <95 \%$ & $1.60(0.65-3.94) p=0.305^{\mathrm{b}}$ & $1.82(0.70-4.74)^{\mathrm{b}} p=0.215^{\mathrm{b}}$ \\
\hline
\end{tabular}

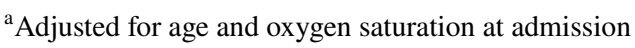

${ }^{\mathrm{b}}$ Single surgical mask group is the reference group 
masks try to protect themselves by wearing double surgical masks instead.

In a study by Dennis et al. to determine vital sign reference intervals in term pregnant women, the average respiratory rate was found to be $18 \pm 1.5 \mathrm{per} / \mathrm{minute}$ [16]. This is a higher value than for non-pregnant individuals. However, the use of N95 masks has been shown in some studies to slightly increase the respiratory rate [15]. The respiratory rate in the present study seems to be compatible with the physiological increase in a term pregnancy.

With these findings, it seems difficult to say that the use of double masks in pregnant women has clinical significance in terms of maternal oxygen saturation levels. Studies with maternal blood gas may contribute to this issue. In addition, an evaluation of fetal oxygenation could be a guide in future studies.

In a study conducted in a non-pregnant population, it was found that wearing various respiratory protection equipment increased heart rate [17]. In the aforementioned study, this effect was found to be more pronounced, especially with equipment that covers the whole face. Similar results have been obtained in studies with N95 masks [13, 15]. In another study, it was stated that the heart rate of individuals wearing SM was lower than that with N95 [4]. In the present study, neither single nor double SM had a significant effect on maternal heart rate. A feeling of shortness of breath (air hunger) begins in the first or second trimester in 60-70 percent of pregnant women, the frequency increases in the second trimester, and then is generally stable in the third trimester [18]. Therefore, mask tolerance in pregnant women is expected to be less than in non-pregnant women. In the current study, mask tolerance was significantly less in the double SM group. The absolute humidity rate inside surgical masks is lower than in N95 masks [19]. Mayer et al. stated that as the temperature increases, the tolerance of the mask decreases [20]. Therefore, different results may occur in different climates. This study was conducted in autumn and winter.

The strengths of this study are that it is prospective and it is the largest study on surgical masks in pregnant women. However, this study has some limitations. Although there was no difference in APGAR scores between the groups, the fetal effects of maternal oxygen saturation (such as Doppler studies) were not evaluated in the study. Moreover, the maternal blood gas evaluation was not performed. The effect of single or double SM use on the different trimesters of pregnancy was not tested. Studies involving respiratory mask groups (such as FFP2, FFP3) are needed.

\section{Conclusion}

It was observed that the single surgical mask did not significantly reduce oxygen saturation in pregnant women at term. However, oxygen saturation decreases significantly in pregnant women using double surgical masks. There was no significant difference in the number of patients whose oxygen saturation was below 95 in the double SM group.

Acknowledgements The authors would like to thank Dr. Anita L. Akkas (Middle East Technical University (ret), Ankara, Turkey) for contributing to the English editing.

Author contributions All authors contributed significantly. MMI participated in the study design, performed the experiment, analyzed the data and wrote the manuscript. BÖ, EBÖ, MG, and EF participated in and contributed to data collecting, literature review, and editing the report. AA revised the manuscript.

Funding None.

\section{Declarations}

Conflict of interest The authors have no conflicts of interest.

\section{References}

1. Wang C, Horby PW, Hayden FG, Gao GF (2020) A novel coronavirus outbreak of global health concern. Lancet 395(10223):470-473

2. Esposito S, Principi N, Leung CC, Migliori GB (2020) Universal use of face masks for success against COVID-19: evidence and implications for prevention policies. Eur Respir J 55(6):2001260

3. Koo JR, Cook AR, Park M, Sun Y, Sun H, Lim JT, Tam C, Dickens BL (2020) Interventions to mitigate early spread of SARS-CoV-2 in Singapore: a modelling study. Lancet Infect Dis 20(6):678-688

4. Li Y, Tokura H, Guo YP, Wong AS, Wong T, Chung J, Newton E (2005) Effects of wearing N95 and surgical facemasks on heart rate, thermal stress and subjective sensations. Int Arch Occup Environ Health 78(6):501-509. https://doi.org/10.1007/ s00420-004-0584-4

5. Lypp A, Edwards P (2005) Disposable surgical face masks: a systematic review. ORNAC J 23(3):20

6. Organization WH (2020) Advice on the use of masks in the context of COVID-19: interim guidance, 6 April 2020. World Health Organization

7. Greenhalgh T, Schmid MB, Czypionka T, Bassler D, Gruer L (2020) Face masks for the public during the covid-19 crisis. BMJ 369:m1435

8. Breslin N, Baptiste C, Gyamfi-Bannerman C, Miller R, Martinez R, Bernstein K, Ring L, Landau R, Purisch S, Friedman AM, Fuchs K, Sutton D, Andrikopoulou M, Rupley D, Sheen JJ, Aubey J, Zork N, Moroz L, Mourad M, Wapner R, Simpson LL, D'Alton ME, Goffman D (2020) Coronavirus disease 2019 infection among asymptomatic and symptomatic pregnant women: two weeks of confirmed presentations to an affiliated pair of New York City hospitals. Am J Obstet Gynecol MFM 2(2):100118. https:// doi.org/10.1016/j.ajogmf.2020.100118 
9. Allotey J, Stallings E, Bonet M, Yap M, Chatterjee S, Kew T, Debenham L, Llavall AC, Dixit A, Zhou D, Balaji R, Lee SI, Qiu X, Yuan M, Coomar D, van Wely M, van Leeuwen E, Kostova E, Kunst H, Khalil A, Tiberi S, Brizuela V, Broutet N, Kara E, Kim CR, Thorson A, Oladapo OT, Mofenson L, Zamora J, Thangaratinam S (2020) Clinical manifestations, risk factors, and maternal and perinatal outcomes of coronavirus disease 2019 in pregnancy: living systematic review and meta-analysis. BMJ 370:m3320. https://doi.org/10.1136/bmj.m3320

10. Guan W-j, Ni Z-y, Hu Y, Liang W-h, Ou C-q, He J-x, Liu L, Shan H, Lei C-1, Hui DS (2020) Clinical characteristics of coronavirus disease 2019 in China. N Engl J Med 382(18):1708-1720

11. Person E, Lemercier C, Royer A, Reychler G (2018) Effect of a surgical mask on six minute walking distance. Rev Mal Respir 35(3):264-268

12. Chen Y, Yang Z, Wang J, Gong H (2016) Physiological and subjective responses to breathing resistance of N95 filtering facepiece respirators in still-sitting and walking. Int J Ind Ergon 53:93-101

13. Roberge RJ, Kim J-H, Powell JB (2014) N95 respirator use during advanced pregnancy. Am J Infect Control 42(10):1097-1100

14. Tong PSY, Kale AS, Ng K, Loke AP, Choolani MA, Lim CL, Chan YH, Chong YS, Tambyah PA, Yong E-L (2015) Respiratory consequences of N95-type Mask usage in pregnant healthcare workers-a controlled clinical study. Antimicrob Resist Infect Control 4(1):48. https://doi.org/10.1186/s13756-015-0086-Z

15. Toprak E, Bulut AN (2020) The effect of mask use on maternal oxygen saturation in term pregnancies during the COVID-19 process. J Perinat Med. https://doi.org/10.1515/jpm-2020-0422
16. Dennis A, Hardy L (2016) Defining a reference range for vital signs in healthy term pregnant women undergoing caesarean section. Anaesth Intensive Care 44(6):752-757. https://doi.org/10. $1177 / 0310057 \times 1604400619$

17. Khodarahmi B, Dehghan H, Motamedzadeh M, Zeinodini M, Hosseini SM (2013) Effect of respiratory protection equipments wear on heart rate in different workload. Int J Environ Health Eng 2(1):26

18. Simon PM, Schwartzstein RM, Weiss JW, Fencl V, Teghtsoonian M, Weinberger SE (1990) Distinguishable types of dyspnea in patients with shortness of breath. Am Rev Respir Dis 142(5):1009-1014. https://doi.org/10.1164/ajrccm/142.5.1009

19. Li Y, Wong T, Chung J, Guo YP, Hu JY, Guan YT, Yao L, Song QW, Newton E (2006) In vivo protective performance of N95 respirator and surgical facemask. Am J Ind Med 49(12):1056-1065. https://doi.org/10.1002/ajim.20395

20. Meyer JP, Héry M, Herrault J, Hubert G, François D, Hecht G, Villa M (1997) Field study of subjective assessment of negative pressure half-masks. Influence of the work conditions on comfort and efficiency. Appl Ergon 28(5-6):331-338. https://doi.org/10. 1016/s0003-6870(97)00007-0

Publisher's Note Springer Nature remains neutral with regard to jurisdictional claims in published maps and institutional affiliations. 